\title{
Erratum to: Effects of Combined Pulse Electromagnetic Field Stimulation Plus Glutamine on the Healing of Colonic Anastomosis in Rats
}

\author{
Sadullah Girgin • Ercan Gedik • Hayrettin Ozturk • \\ Veysi Akpolat · Ebru Kale · Huseyin Buyukbayram • \\ Salih Celik
}

Published online: 20 April 2010

(C) Springer Science+Business Media, LLC 2010

Erratum to: Dig Dis Sci (2009) 54:745-750

DOI 10.1007/s10620-008-0412-x

The family name of the fourth author is listed incorrectly in the original article as Akbulut. The correct family name is Akpolat, as shown in this erratum.

The online version of the original article can be found under doi:10.1007/s10620-008-0412-x.

\section{S. Girgin · E. Gedik}

Department of General Surgery, Medical School,

Dicle University, Diyarbakir, Turkey

H. Ozturk $(\bowtie)$

Department of Pediatric Surgery, Medical School,

Abant Izzet Baysal University, 14280 Bolu, Turkey

e-mail: ozturkhayrettin@hotmail.com

\section{Akpolat}

Department of Biophysics, Medical School, Dicle University,

Diyarbakir, Turkey

E. Kale $\cdot$ S. Celik

Department of Biochemistry, Medical School, Dicle University,

Diyarbakir, Turkey

H. Buyukbayram

Department of Pathology, Medical School, Dicle University,

Diyarbakir, Turkey 